\title{
Designing and Demonstrating a Master Student Project to Explore Carbon Dioxide Capture Technology
}

Florine Asherman ${ }^{1}$, Gilles Cabot ${ }^{3}$, Cyril $\mathrm{Crua}^{4}$, Lionel Estel ${ }^{1,2}$, Charlotte Gagnepain ${ }^{1}$, Thibault Lecerf ${ }^{1}$, Alain Ledoux ${ }^{1,2}$, Sébastien Leveneur ${ }^{1,2,5, *}$, Marie Lucereau ${ }^{1}$, Sarah 5 Maucorps $^{1}$, Mélanie Ragot ${ }^{1}$, Julie Syrykh ${ }^{1}$, Manon Vige $^{1}$

${ }^{1}$ MRIE-Maîtrise des Risques Industriels et Environnementaux, INSA Rouen, BP08, Avenue de l'Université, 76801 Saint-Etienne-du-Rouvray, France

102 LSPC-Laboratoire de Sécurité des Procédés Chimiques, EA4704, INSA Rouen, BP08, Avenue de l’Université, 76801 Saint-Etienne-du-Rouvray, France. Tel: +332 329566 54;

Fax: +33 2329566 52; E-mail: sebastien.leveneur@insa-rouen.fr

3 CORIA-UMR6614, Université et INSA de Rouen, 76801 Saint-Etienne du Rouvray cedex, France;

${ }^{4}$ School of Computing, Engineering and Mathematics, University of Brighton, Brighton BN2 4GJ, UK

${ }^{5}$ Laboratory of Industrial Chemistry and Reaction Engineering, Process Chemistry Centre, Åbo Akademi University, Biskopsgatan 8, FI-20500 Åbo/Turku, Finland; 


\section{ABSTRACT}

The rise in carbon dioxide $\left(\mathrm{CO}_{2}\right)$ concentration in the Earth's atmosphere, and the associated strengthening of the greenhouse effect, requires the development of low carbon technologies. New carbon capture processes are being developed to remove $\mathrm{CO}_{2}$ that would otherwise be emitted from industrial processes and fossil fuel power stations. Given the increasing importance of this technology we report on a new educational project which aimed to instill greater awareness of the role of $\mathrm{CO}_{2}$ in climate change, whilst stimulating student interest in science, technology, engineering, and the environment. The project was carried out by master students, i.e., Cool $\mathrm{L}_{\mathrm{C}} \mathrm{p}$ team, who contributed to the design and manufacture of a pilot plant that demonstrates the basic operation of an amine scrubbing plant. The main goal of the project was to develop educational material and presentations for a range of audiences, from primary school to university students and academics. In this article we present the project team's approach to design, commission and deliver the pilot plant and educational material, as well as the feedback received from 267 students from a primary school and a university. We provide supplementary material to enable other educators to recreate our pilot plant design. 
ABSTRACT GRAPHIC

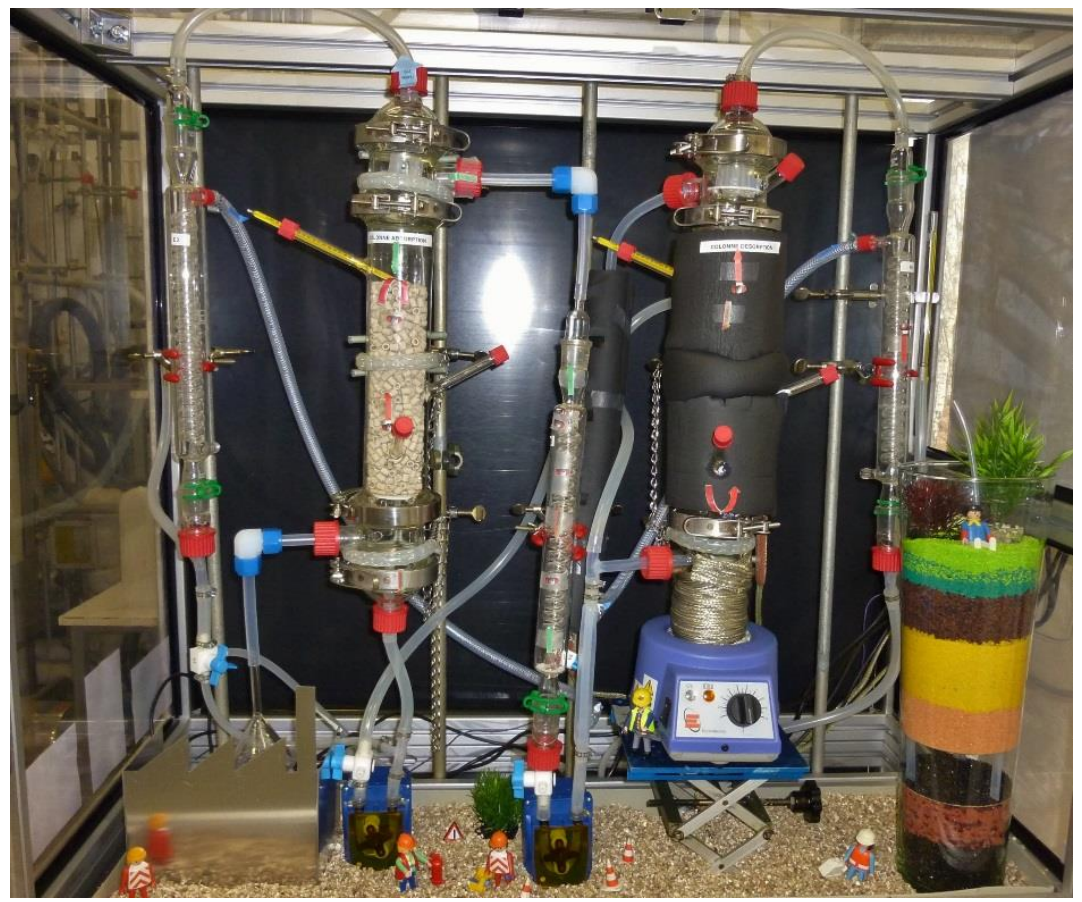




\section{KEYWORDS}

General Public, Elementary / Middle School Science, High School / Introductory Chemistry, Chemical Engineering, Environmental Chemistry, Public Understanding / Outreach, Communication / Writing, Laboratory Equipment / Apparatus. 


\section{INTRODUCTION}

The increase of the greenhouse effect is known as a worldwide issue, partly due to human activities. ${ }^{1-4}$ Global warming, sustainable development or greenhouse effect are taught at primary school or university. To reduce the consequences of human activities on the climate, it is not only essential to develop new technologies but also to raise awareness among the young generation and the non-scientific community. ${ }^{5}$ At our department, we have reached to the conclusion that it could be an excellent challenge for master students to carry out such project.

The $\mathrm{CoO}_{\mathrm{L}} \mathrm{Cap}$ project, which is a kind of acronym for $\mathrm{CO}_{2}$ capture in liquid phase, was created. This project was carried out by successively two groups of eight master students of the engineering school INSA Rouen (France). The ambition of this project was to introduce carbon capture technologies to different audiences by having an interactive dialogue. This project had three main objectives:

- To experience a team project for master students involving client relationship,

- To build transportable lab-scale pilot based on chemical absorption and desorption of $\mathrm{CO}_{2}$ (Figure 1),

80 - To demonstrate and explain the technologies ${ }^{6}$ to broad audiences with a pedagogical strategy.

For the sake of clarity, the master students who have organized the project are named $\mathrm{Coo}_{\mathrm{L}} \mathrm{Cap}$ team in the manuscript. Several events were organized by the $\mathrm{CoO}_{\mathrm{L}} \mathrm{Cap}$ team to meet groups of students from primary school to university, to present and show the pilot. The purpose of the demonstrations included developing children's interest in science by showing them that chemistry can be used to reduce the greenhouse effect. Moreover, the instrumentation used to make the pilot work was presented. 
The goal of this article is mainly to present the carbon capture technologies and the pilot. The work team experience of the $\mathrm{CoO}_{\mathrm{L}} \mathrm{Cap}$ project is briefly discussed.

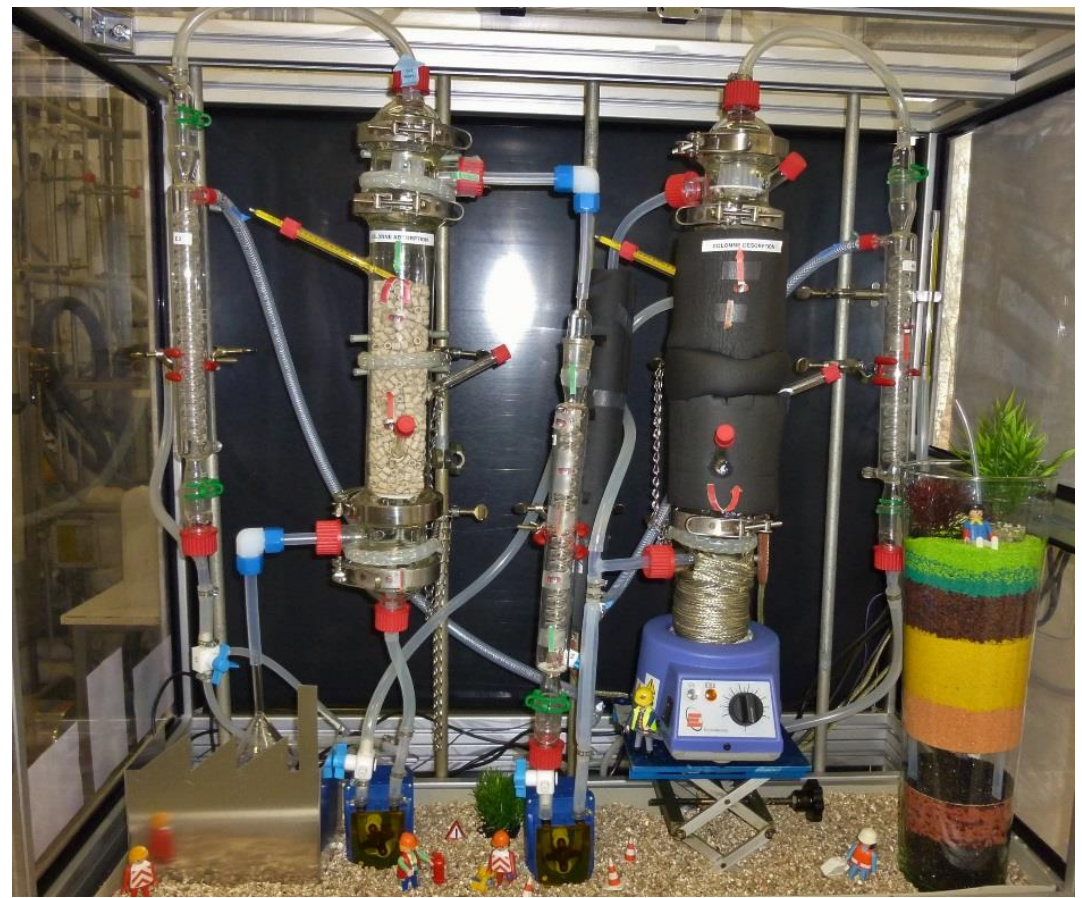

Figure 1. Carbon dioxide capture pilot plant designed and manufactured by the student project team. 
This chapter introduces the $\mathrm{Coo}_{\mathrm{L}} \mathrm{Cap}$ project framework. At our university, master students should perform a project, named PIC project, which is a certified INSA. The team project is composed of eight students from the master of industrial and environmental risks management. The project is a one academic year and two workdays per week are dedicated to realize the PIC project. The PIC project should follow a quality approach, i.e. ISO 9001-2008. The PIC students are supervised by a quality supervisor during their project in order to obtain the certification at the end. A teaching staff (scientific supervisor) supervises the team project to ensure extensive theoretical basis.

105 A contract is signed with an industrial or academic client to define the different products to deliver. The evaluation of the PIC project is done four times per year. For the $\mathrm{Coo}_{\mathrm{L}} \mathrm{Cap}$ project, the client was a European program, named E3C3. One of E3C3 goals was to promote sustainable development, and more precisely, to improve knowledge and create tools to carry out clean combustion and biomass combustion. The $\mathrm{CoO}_{\mathrm{L}} \mathrm{Cap}$ team was also mentored by a communication teacher to improve the communication skills of the team. It included interpersonal communication in the team and with the client. Also, the communication teacher helped the team to carry out presentations about the progress of the project. In the case of the $\mathrm{CoO}_{\mathrm{L}} \mathrm{Cap}$ project, the laboratory manager has helped the student for the pilot building. Figure 2 illustrates the interaction between the different actors of the $\mathrm{CoO}_{\mathrm{L}} \mathrm{Cap}$ project. 


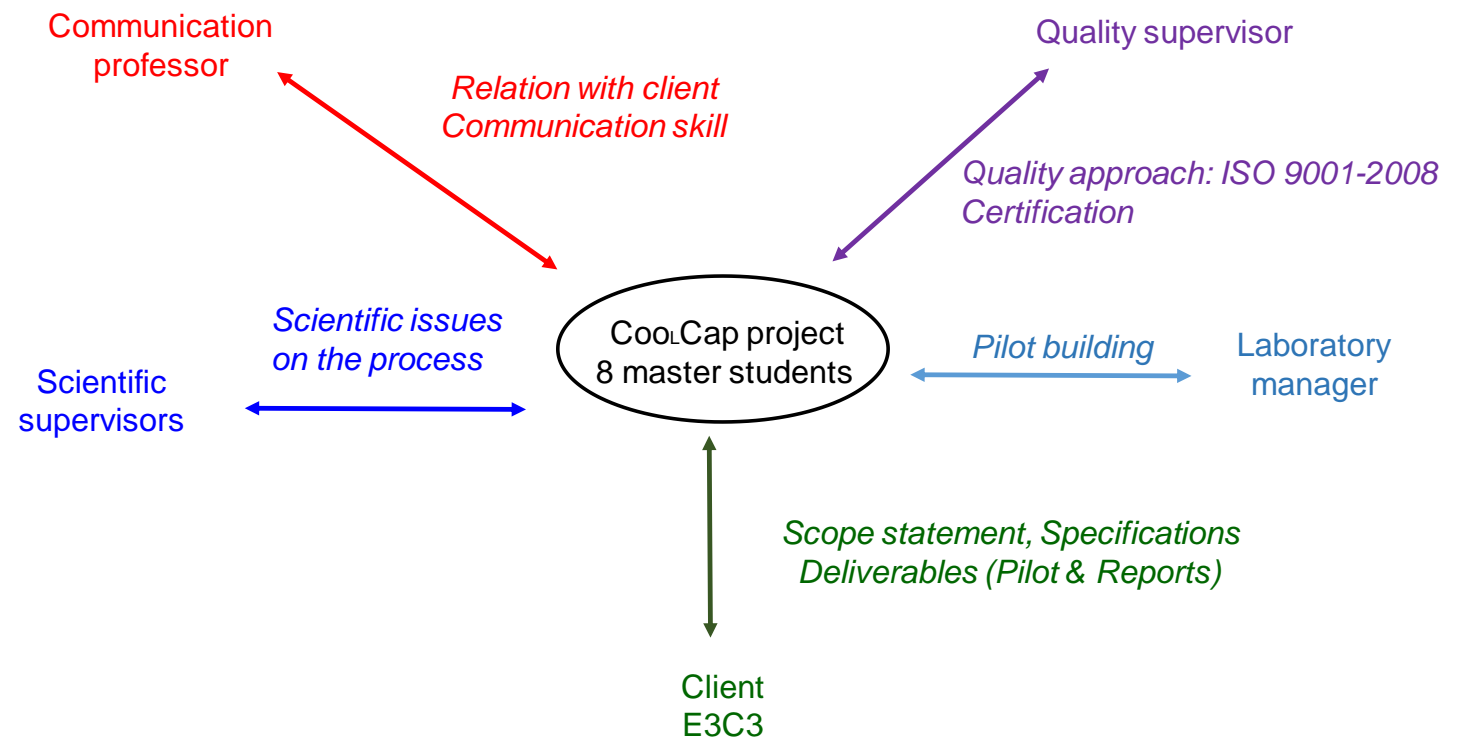

Figure 2. Different actors participating to the Cool_Cap project. 


\section{DEVELOPMENT OF A PILOT FOR CARBON CAPTURE}

Carbon capture is a decarbonization technology (also known as decarburization technology) that has been designed to capture carbon dioxide generated by combustion reactions in industrial applications ${ }^{6}$. Therefore, this technology abates $\mathrm{CO}_{2}$ emissions into the atmosphere. In 2011, there were $89 \mathrm{CO}_{2}$ capture and storage (CCS) demonstration projects or pilots in USA. ${ }^{7}$ For example, a CCS technology has been in place since 1996 on the Sleipner offshore gas field (Norway) located in the central North Sea. On this field, $\mathrm{CO}_{2}$ is both captured and stored into a dedicated well. ${ }^{8}$ More recently, a carbon capture power plant was launched in 2014 at Boundary Dam Power Station in Saskatchewan (Canada), and its goal is to capture 1 million tons of $\mathrm{CO}_{2}$ every year, to reduce $\mathrm{CO}_{2}$ emissions by $90 \% .^{8}$ In 2011 the Laboratory of Chemical Process Safety (Laboratoire de Sécurité des Procédés Chimiques LSPC, INSA Rouen - Université Rouen) has contributed to the scale up of a large-scale pilot, in association with Veolia Environment, for a waste incinerator in Normandy (France). $9-10$

Different chemical processes can be used to capture and regenerate pure $\mathrm{CO}_{2}$. A suitable solution to integrate carbon capture into an existing combustion process, is to modify the post-combustion unit (Figure 3). It is also known as the downstream modification of the existing $\mathrm{CO}_{2}$ emitting process. The post-combustion carbon capture 140 is based on absorption and desorption phenomena. Those chemical principles are used to absorb $\mathrm{CO}_{2}$ and separate it from other gases resulting from a combustion reaction. The flue gas is first absorbed into a solvent, e.g. monoethanolamine (MEA), and $\mathrm{CO}_{2}$ can then be regenerated by altering the thermodynamic conditions of the $\mathrm{CO}_{2}$-loaded solvent (e.g. by increasing its temperature). ${ }^{11}$ 
Design and operation of the carbon capture and storage pilot plant

The pilot plant performed the carbon dioxide capture process through absorption using a chemical solvent. An amine-based solvent was selected to absorb $\mathrm{CO}_{2}$ due to the strong chemical affinity between the two compounds. There are different types of amine that allow $\mathrm{CO}_{2}$ capture. Most of the commercial plants use monoethanolamine (MEA). This aqueous primary amine is commonly used for post-combustion separation processes ${ }^{12-13}$, as it is highly reactivity with $\mathrm{CO}_{2}$, inexpensive and readily available. ${ }^{14}$ The absorption occurs in accordance with the following reaction equation:

$$
2\left(\mathrm{C}_{2} \mathrm{H}_{4} \mathrm{OH}\right) \mathrm{NH}_{2}+\mathrm{CO}_{2} \rightleftarrows\left(\mathrm{C}_{2} \mathrm{H}_{4} \mathrm{OH}\right) \mathrm{NH}_{3}{ }^{+}+\left(\mathrm{C}_{2} \mathrm{H}_{4} \mathrm{OH}\right) \mathrm{NHCOO}^{-}
$$

The $\mathrm{CO}_{2}$ present in the flue gases is normally pumped into the carbon dioxide scrubber, and then cooled down by a heat exchanger. The cooled effluent gas is then fed into the bottom of an absorption column and propagates up through packing material. A counter flow of MEA is produced by nozzles located at the top of the absorption column and propagates down, contacting with the gases through the packing material. The packing material improves contact between the gas and the liquid phases, thus increasing the absorption rate of the $\mathrm{CO}_{2}$. The $\mathrm{CO}_{2}$-loaded MEA flows down to the bottom of the column, while the decarbonized effluent gas rises up to the top of the column and can be released from the scrubber. The absorption generally occurs at atmospheric pressure and at temperature of approximately $50^{\circ} \mathrm{C}$.

The loaded-MEA is then pumped and heated up to $70^{\circ} \mathrm{C}$ before being introduced at the top of an air stripper. The liquid in the column is heated to $100^{\circ} \mathrm{C}$, and the pressure remains at 1 bar. The increased temperature activates the desorption of $\mathrm{CO}_{2}$ from the 170 MEA, which remains in the liquid state. Once released, the gaseous $\mathrm{CO}_{2}$ can be extracted from the top of the desorption column. The extracted gas is then cooled down with a water heat exchanger to condensate the water and solvent steam, and to obtain 
pure $\mathrm{CO}_{2}$ gas. The $\mathrm{CO}_{2}$-lean MEA that remains in the desorption column is pumped out of the column and cooled down through a heat exchanger using the water and $\mathrm{CO}_{2}$-rich MEA flows. MEA is then regenerated and returned to the absorption column to be reused in a closed-loop cycle (Figure 3). ${ }^{9-11,13-15}$

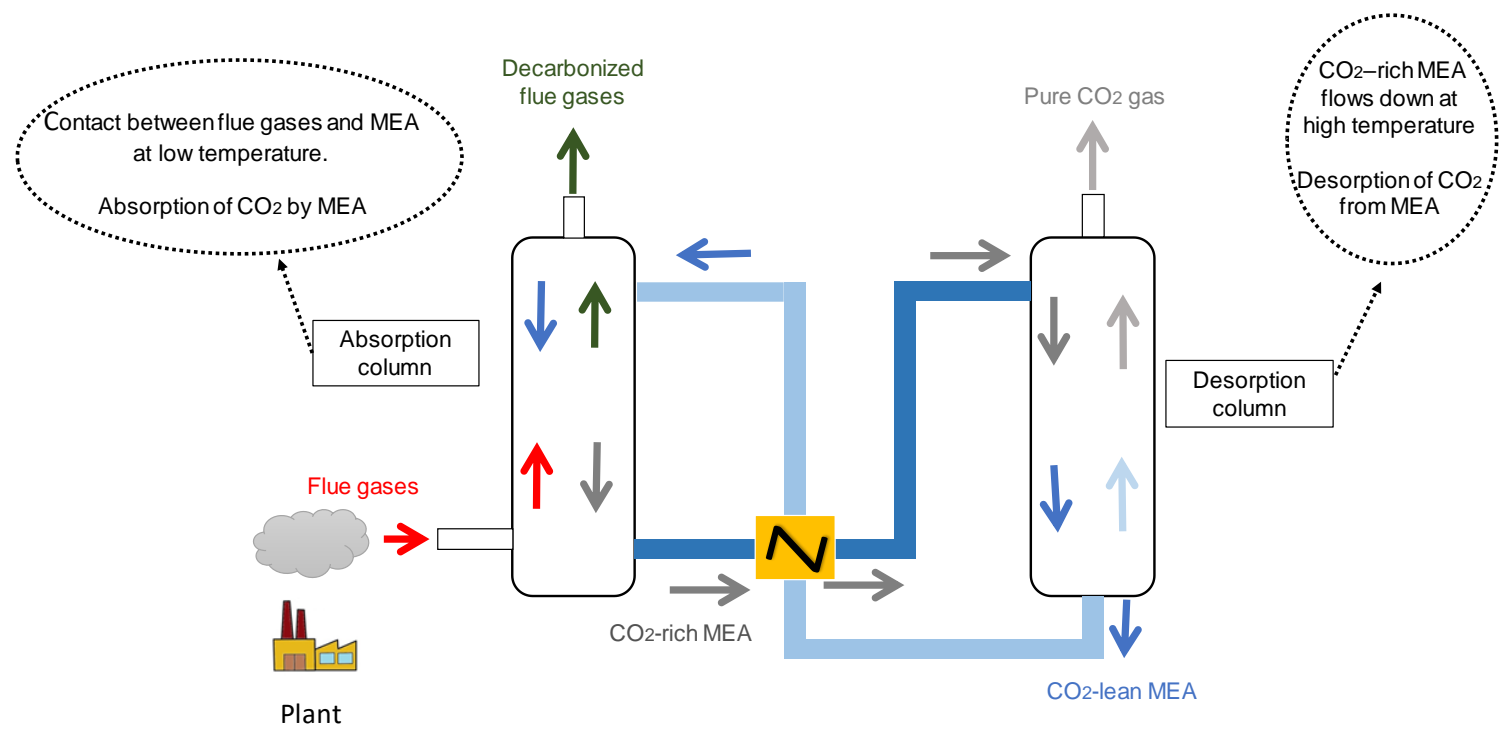

Figure 3. Schematic of the carbon capture chemical process.

Adapting the pilot plant for educational outreach purposes

The lab-scale pilot plant described above, and shown in Figure 1, was commissioned by the $\mathrm{CoO}_{\mathrm{L}} \mathrm{Cap}$ team as a visual aid to demonstrate concretely the theoretical and operating principles of carbon capture to a broad audience. The pilot was placed in a mobile cabinet (1.2 $\mathrm{m}$ long, $1.8 \mathrm{~m}$ high, $0.6 \mathrm{~m}$ deep) fitted with casters to facilitate transportation.

The design and pilot appearance was specifically customized like a pilot plant to make it more informative to young audiences. Industrial activity was illustrated with a miniature factory made of steel. An alcohol lamp burned to represent industrial 

to the absorption column.

The MEA can also be dyed yellow to improve the visualization of its circulation through the pilot plant, by the addition of a small amount of fluorescein (a few milligrams).

At the end of the desorption process, experiments were used to demonstrate that the gas extracted from the desorption column contains mostly $\mathrm{CO}_{2}$. For example, limewater was used in a laboratory flask and connected to the end of the process. Limewater becomes cloudy when exposed to $\mathrm{CO}_{2}$ because of the formation of a precipitate, thus demonstrating the presence of $\mathrm{CO}_{2}$ in the gas extracted from the desorption column.

Moreover, to illustrate the geological storage of $\mathrm{CO}_{2}$ the outlet of the desorption column was connected to a vase full of sand, representing geological layers. A vacuum is generated in the center of the vase to draw the gas through the vase. This is the technology of carbon capture and storage (CCS). The transformation or valorization of $205 \mathrm{CO}_{z}$ to chemicals, fuels or its use as a solvent was also discussed. This is the technology of carbon capture and utilization (CCU). 


\section{EDUCATIONAL APPROACH}

210 The demonstration had a number of education objectives:

- To raise awareness of the greenhouse effect among children.

- To present a new technology that can help to reduce $\mathrm{CO}_{2}$ emissions.

- To show that chemistry can be useful to find concrete solutions to problems such as global warming.

- To share information about chemical principles: absorption and desorption phenomena between $\mathrm{CO}_{2}$ and an amine-based solvent.

- To promote science and chemistry to children.

The demonstrations were tailored to the age of the audience, but always based on the same framework. The greenhouse effect and global warming were explained or reminded as an introduction, and then the carbon capture technology was presented using the pilot plant and some interactive chemical experiments. The ways in which we adapted our pedagogical approach for primary school, high school and university students were based on effective communication strategies and recommended good practices $^{16-17}$, and described in the next sections.

Presentation carried out

The $\mathrm{CoO}_{\mathrm{L}} \mathrm{Cap}$ team carried out presentations to several groups in schools and universities:

- Four groups of 10 to 30 high school students.

- Two groups of 10 and 17 masters students.

- Three groups of 15 to 30 bachelor students.

- Eight groups of 30 primary school students. 
The project team took part in the French national science festival "Fête de la Science" for three days in October 2014. This included presentations and demonstrations to several hundred students from primary school to university levels. In the following sections we present our approach to tailoring the learning experience to audiences from a primary school and a high school.

Primary school

The $\mathrm{CoO}_{\mathrm{L}} \mathrm{Cap}$ team carried out presentations and interactive demonstrations at a British primary school, with students from 7 to 12 years of age. They were grouped into classes of 30 students of similar ages. The aim was to make the presentation as interactive as possible and to have a series of discussions with the children. In order to maintain the younger audience's attention the demonstrations lasted no more than 30 minutes. Prior to these presentations, the learning objectives and lesson plans were presented to the class teachers, so they could introduce the topic to provide complementary information about chemistry fundamentals, including chemical reactions or basic thermodynamics.

The first part of the demonstration reviewed concepts of the greenhouse effect and global warming, in order to make the children aware of these environmental issues, and to explain the need for $\mathrm{CO}_{2}$ capture technologies. First, the project team asked what they already knew about the greenhouse effect and global warming. The majority of students already had notions about climate change. The purpose was to add scientific notions about solar radiation, greenhouse gases and the global increase in the Earth's surface temperature. This discussion was supported by a model (Figure 4) which facilitated the step-by-step demonstration of the propagation and reflection of the Sun's rays through the atmosphere. Different solutions to reduce $\mathrm{CO}_{2}$ emissions were discussed with the children, the CCS and CCU technologies were then presented as a 
possible solution to diminish the release of industrially-generated $\mathrm{CO}_{2}$ into the atmosphere.

In the second part of the demonstration, the operating principle of carbon capture was explained and demonstrated using the pilot plant. This helped the children better understand the various steps of the process, and how the absorption and desorption phenomena occur in such plants. From a chemical point of view, only the absorption and desorption phenomena were described through the chemical reaction and the affinity between MEA and $\mathrm{CO}_{2}$. Images were used to support the explanation of this chemical principle. One example we used was to compare the solvent to a train which collected $\mathrm{CO}_{2}$ 'passengers' inside the absorption column, and dropping them off in the desorption column. Another way to explain this process was to suggest that MEA swallows $\mathrm{CO}_{2}$ molecules in the absorption column and releases them in the desorption column. After explaining the chemical process, $\mathrm{CO}_{2}$ storage was then explained with the visual support from a vase full of colored sands, representing the sedimentary layers and the well-used to store the extracted carbon dioxide.

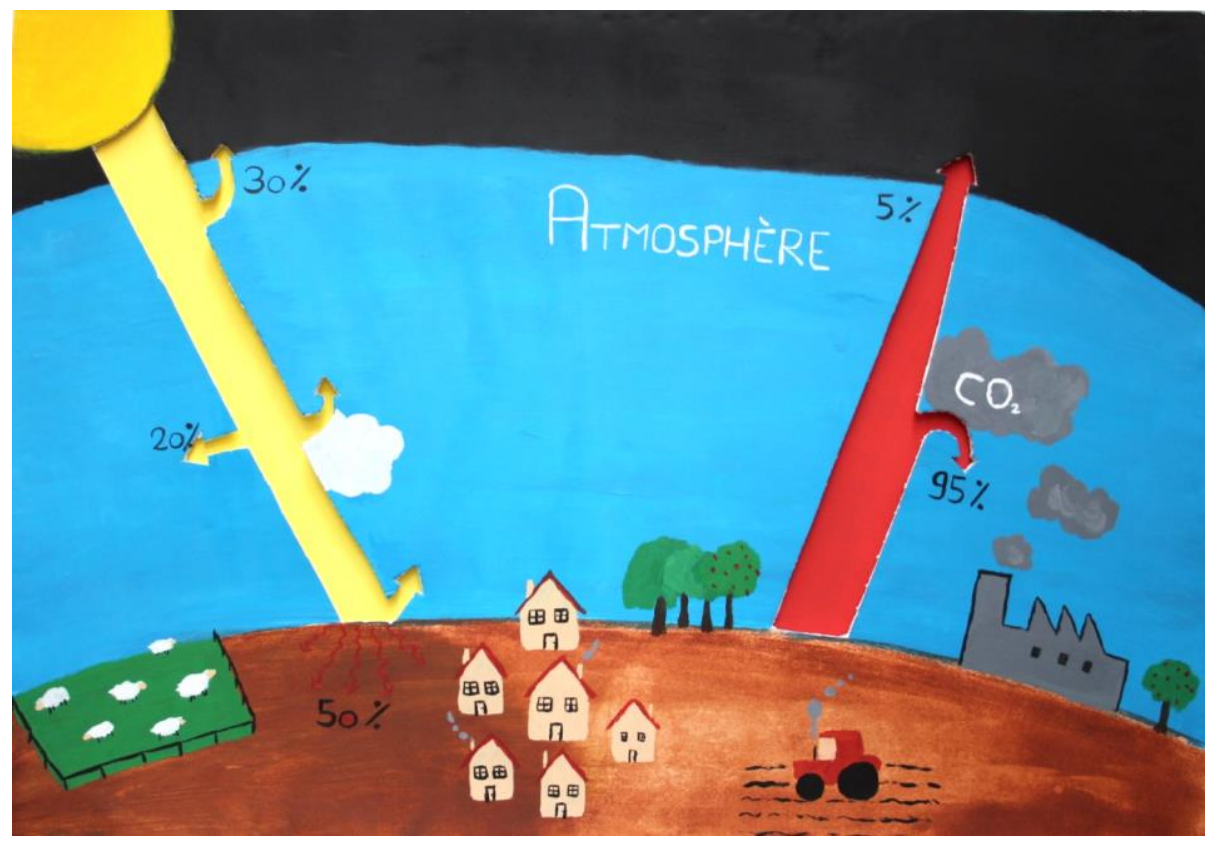

Figure 4. Model used to explain the greenhouse effect. 
The third part of the presentation consisted in carrying out two experiments in order to highlight the phenomena of absorption and desorption. Those simple experiments helped the public engage with the presentation and participate in the demonstration.

Experiment to show the absorption phenomenon

The first experiment highlighted the phenomenon of absorption of carbon dioxide by MEA in the absorption column. For this purpose, we used $20 \mathrm{~mL}$ of a sodium hydroxide solution at a concentration of $2 \mathrm{~mol} \cdot \mathrm{L}^{-1}$. Since $\mathrm{NaOH}$ is a base, it has similar properties to MEA regarding the absorption of $\mathrm{CO}_{2}{ }^{18}$, but it has the advantage of being less corrosive and toxic than MEA. Thus the experiments can be carried out more safely than with MEA.

The experiment required two empty plastic bottles of $0.5 \mathrm{~L}$ and one volumetric pipette. One of the plastic bottles was filled with $\mathrm{CO}_{2}$ in advance, while the second bottle was full of air. Using the pipette, $10 \mathrm{~mL}$ of the sodium hydroxide solution was then inserted in both bottles, and the bottles were sealed. Two students were asked to volunteer to shake the bottles for few seconds. Then, the audience could compare the two bottles: one bottle had contracted and became warmer, while the other one had remained unchanged (Figure 5). The $\mathrm{NaOH}$ solution absorbs $\mathrm{CO}_{2}$ but not air, hence only the bottle that contained $\mathrm{CO}_{2}$ had contracted. This interactive demonstration helped support the explanation that liquid solvents can absorb gaseous $\mathrm{CO}_{2}$. This simple experiment provided a visual support for explaining that the bottle full of $\mathrm{CO}_{2}$ had contracted due to the $\mathrm{CO}_{2}$ molecules being absorbed by the $\mathrm{NaOH}$ solution. As this is an exothermic reaction, it generated heat and warmed the bottle up. This phenomenon 300 was described with an increasing level of detail to high school and university students who have prior knowledge of chemical reactions. 


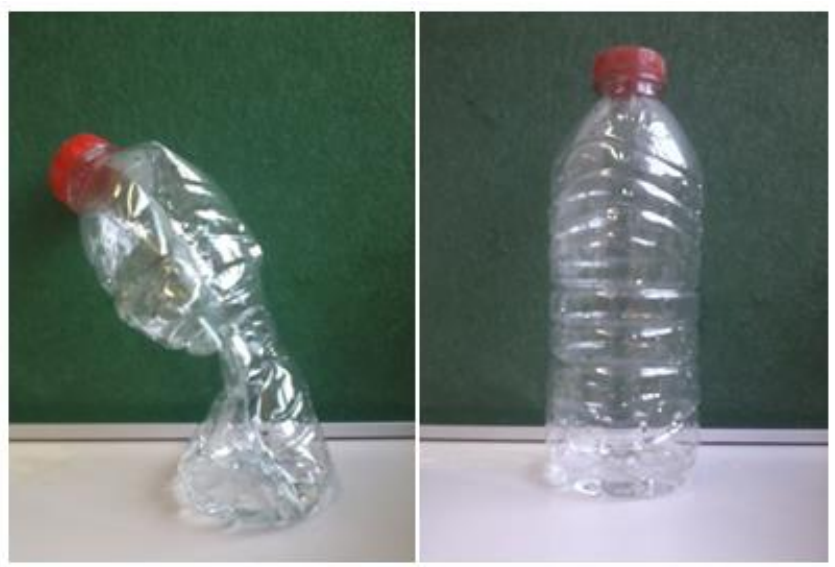

Figure 5. Plastic bottles filled with sodium hydroxide solution and $\mathrm{CO}_{2}$ (left), and filled with sodium hydroxide solution and air (right). The $\mathrm{NaOH}$ solution absorbs $\mathrm{CO}_{2}$ but not air, hence only the bottle that contains $\mathrm{CO}_{2}$ has contracted. This interactive demonstration helped support the explanation that liquid solvents could absorb gaseous $\mathrm{CO}_{2}$.

\section{Experiment to show the desorption phenomenon}

The second experiment demonstrated the phenomenon of $\mathrm{CO}_{2}$ desorption. As mentioned previously, $\mathrm{CO}_{2}$ can transfer into the gas phase by increasing the temperature of the solvent. In order to demonstrate this process, a beaker was filled with cold water (approximately $5^{\circ} \mathrm{C}$ ) while another one was filled with hot water (approximately $40^{\circ} \mathrm{C}$ ). Then, two test tubes were filled with a soft drink (carbonated beverage) and partially closed with a pierced lid. These two test tubes were turned upside down, blocking the pierced lid with the thumb, and plunged into the two water beakers. The experimenter could then release the pierced lids, and let the desorption phenomenon occurred. After a few minutes, it could be observed that the level of soft drink in the test tube plunged in the hot water beaker decreased, while the level of soft drink in the cold test tube remained constant (Figure 6).

This experiment demonstrated to the children the influence of temperature on the solubility of carbon dioxide in a liquid solvent, and that the heat enabled the desorption of $\mathrm{CO}_{2}$. As a result of this desorption the pressure above the soft drink increased, and the level of liquid in the test tube reduced. 


\section{Test tube filled with soft drink}
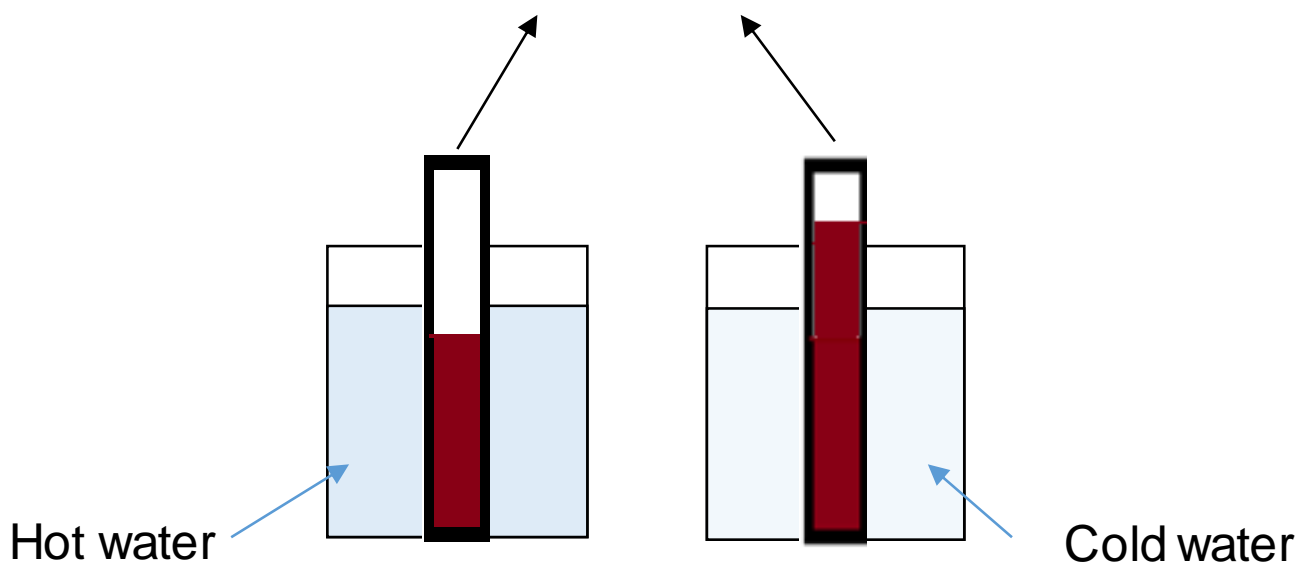

Figure 6. Schematic representation of the desorption experiment with a warm water beaker (left) and a cold water beaker (right). This demonstrated the influence of temperature on the solubility of carbon dioxide in a liquid solvent, and that the added heat enabled the desorption of $\mathrm{CO}_{2}$.

High school

The primary school presentation was adapted for older students from high schools and universities. The demonstrations lasted between 45 minutes and one hour, including more technically and scientifically detailed explanations. Since the students already have prior knowledge of the greenhouse effect, the project team presented facts and data about the international context of climate change, and the United Nations' agreements to develop new technologies for the reduction of anthropogenic production of $\mathrm{CO}_{2}$. The $\mathrm{CCS}$ and $\mathrm{CCU}$ technologies were presented as one of the potential solutions. The three carbon capture methods were introduced: the oxyfuel-combustion, precombustion and post-combustion capture. Details were given about the combustion reaction, about the differences between the methods and how they were used in industrial processes. The post-combustion capture was used for the pilot plant. Hence this process was explained in more details, and supported by the pilot plant, with a view of the way the exhaust gases and the solvent propagate through the absorption 
column, the heat exchangers and the air stripper. The chemical reactions and the thermodynamic conditions, such as molecule groups, temperature and pressure, were more detailed than for the younger audience. The topic was also discussed with the students' teachers in order to extend the learning beyond our interactive demonstration, and to cover some of the fundamental principles linked to these chemical processes. Storage and transformation of carbon dioxide were then presented, including the different geological layers that can be used for storage, and the industrial 350 sectors that can reuse carbon dioxide. We observed that the students were particularly interested in the industrial aspects of the technology, such as how to incorporate the system in global industrial processes. They were also interested in the technical details of the carbon capture process. 
In order to evaluate the delivery of our demonstrations and the interest of the students we gave questionnaires to the audience after our presentations. Two types of feedback forms were prepared: one for students under the age of 11 , and one for older students. For the presentation at the primary school, $90 \%$ of the 240 students were satisfied with the presentation and enjoyed the experiments. From the survey, $81 \%$ understood very much the greenhouse effect, $16 \%$ understood a little and $3 \%$ answered they did not understand it. From the survey, $77 \%$ understood very much the $\mathrm{CO}_{2}$ capture and $23 \%$ understood a little (see Figure 2 supporting information).

The feedback for the older audience asked more specific questions, including their level of satisfaction with the presentation: the visual aids, the duration, the exchanges with the team and the level of technical detail. They were also asked if the presentation was adapted to their prior knowledge and if they understood the different elements. To give an example, for 27 master students in mechanical engineering, 96\% were satisfied 370 by the presentation, with $52 \%$ totally satisfied, $44 \%$ very much satisfied and $4 \%$ a little. The talk was globally understood by $96 \%$ of the students, $41 \%$ understood completely, $52 \%$ very much, and $7 \%$ a little. The analysis of the feedback forms indicates that the demonstrations were generally appreciated and well understood (see Figure 3 supporting information). 


\section{CONCLUSIONS}

We presented a new and innovative approach to demonstrate carbon capture technology whilst supporting the learning of chemical processes to a wide range of audiences. The challenges of presenting a complex technology, and the chemical reaction between a liquid solvent and gaseous $\mathrm{CO}_{2}$, to primary school students were overcome through visually simple and hands-on experiments supported by a purposebuilt pilot plant. The educational pilot plant we designed and built can be replicated to demonstrate chemistry notions in a novel and interactive way. The feedback we received from 267 primary school students and master students suggests that the educational approach we have described in this article stimulated student interest in science and technology, while improving their awareness of the challenges posed by the strengthening of the greenhouse effect and the impact on climate change. 
Supporting Information

The following documents can be found as supporting information:

- Construction of carbon dioxide capture pilot plant.

- Equipment for the pilot plant.

- Pilot plant startup procedure.

- Pilot plant shutdown procedure.

- Process flow diagram of the carbon dioxide capture pilot plant.

- Feedback results from masters students in Mechanical Engineering from the University of Brighton (Brighton, UK).

- Feedback results from the students of the Glebe Primary School (Southwick, UK).

\section{AUTHOR INFORMATION}

405 Corresponding Author

*E-mail: sebastien.leveneur@insa-rouen.fr

\section{ACKNOWLEDGMENTS}

This work was supported by the European Regional Development Fund [INTERREG

410 IVA grant 4274]. The authors are particularly grateful to Bruno Daronat for his contribution to the experiment. The authors would like to acknowledge the contributions from the previous project student team, composed of Lucie Alleaume, Jeanne Bertoldi, Charles Briec, Camille Courbet, Mathilde Francois, Ana Gavrilenco, Arnaud Khun, Charlotte Nicolas, and Julien Ribotta. We would also like to thank 415 Ludovic Auvray for proofreading this article. 


\section{REFERENCES}

(1) NASA. Climate Change: How do we know? http://climate.nasa.gov/evidence $420 \quad$ (accessed December 2014).

(2) Intergovernmental Panel on Climate Change (IPCC). Chapter 8 Anthropogenic and Natural Radiative Forcing. In Climate Change 2013: The Physical Science Basis. http://www.ipcc.ch/pdf/assessment-report/ar5/wg1/WG1AR5_Chapter08_FINAL.pdf (accessed December 2014).

(3) American Association for Advancement of Science. AAAS Board Releases New Statement on Climate Change. http://www.aaas.org/news/aaas-board-releases-newstatement-climate-change (accessed December 2014).

(4) United Nations Framework Convention on Climate Change. Kyoto Protocol. http://unfccc.int/kyoto_protocol/items/2830.php (accessed January 2015).

430 (5) Flener-Lovitt, C. Using the Socioscientific Context of Climate Change to Teach Chemical Content and the Nature of Science. J. Chem. Educ. 2014, 91 (10), 1587-1593.

(6) King Abdullah Petroleum Studies, Saud M. Al-Fattah, Murad F. Barghouty, Bashir O. Dabbousi. Chapter 1: CCS in a Global Context. In: Carbon Capture and Storage: Technologies, Policies, Economics, and Implementation Strategies, CRC Press/Balkema: Boca Raton, 2011; pp 3-10.

(7) Zhao, R.; Deng, S.; Zhao, L.; Liu, Y.; Tan, Y. Energy-saving Pathway Exploration of CCS Integrated with Solar Energy: Literature Research and Comparative Analysis. Energy Conversion and Management 2015, 102, 66-80.

(8) Mumford, K.A.; Wu, Y.; Smith, K.H.; Stevens, G.W. Review of Solvent based Carbon440 dioxide Capture Technologies. Front. Chem. Sci. Eng. 2015, 9(2), 125-141.

(9) Aouini, I.; Ledoux, A.; Estel, L.; Mary, S. Pilot Plant Studies for $\mathrm{CO}_{2}$ Capture from Waste Incinerator Flue Gas Using MEA Based Solvent. Oil \& Gas Science and Technology - Rev. IFP Energies nouvelles 2014, 69 (6), 1091-1104. 
(10) Aouini I. Captage du dioxyde de carbone en postcombustion - Application à un incinérateur de déchets industriels. PhD Thesis, LSPC INSA Rouen, 2012.

(11) King Abdullah Petroleum Studies, Saud M. Al-Fattah, Murad F. Barghouty, Bashir O. Dabbousi. Chapter 3: $\mathrm{CO}_{2}$ Capture and Separation. In: Carbon Capture and Storage: Technologies, Policies, Economics, and Implementation Strategies, CRC Press/Balkema: Boca Raton, 2011; pp 119-124.

(12) Nuchitprasittichai, A.; Cremaschi, S. Sensitivity of Amine-based $\mathrm{CO}_{2}$ Capture Cost: The Influences of $\mathrm{CO}_{2}$ Concentration in Flue Gas and Utility Cost Fluctuations. Int. J. Greenhouse Gas Control 2013, 13, 34-43.

(13) Han, C.; Graves, K.; Neathery, J.; Liu, K. Simulation of the Energy Consumption of $\mathrm{CO}_{2}$ Capture by Aqueous Monoethanolamine in Pilot Plant. Energy and Environment $455 \quad$ Research 2011, 1(1), 67-80.

(14) Qi Yang, Susan James, Mathew Ballard, Mark Bown. Attalla M. Chapter 2: Influence of Amine Chemical Structures to Amine Capacities in $\mathrm{CO}_{2}$ Capture. In: Recent Advances in Post-Combustion $\mathrm{CO}_{2}$ Capture Chemistry, American Chemical Society: Washington DC, 2012; pp 29-42.

460 (15) Yeh, J. T.; Pennline, H. W.; Resnik, K. P. Study of $\mathrm{CO}_{2}$ Absorption and Desorption in a Packed Column. Energy Fuels 2001, 15 (2), 274-278.

(16) Schwan, S.; Grajal, A.; Lewalter, D. Understanding and Engagement in Places of Science Experience: Science Museums, Science Centers, Zoos, and Aquariums. Educational Psychologist 2014, 49(2), 70-85.

465 (17) Sinatra, G.M.; Kienhues, D.; Hofer, B.K. Addressing Challenges to Public Understanding of Science: Epistemic Cognition, Motivated Reasoning, and Conceptual Change. Educational Psychologist 2014, 49(2), 123-138. 
(18) Mahmoudkhani, M.; Keith D.W. Low-energy Sodium Hydroxide Recovery for $\mathrm{CO}_{2}$ Capture from Atmospheric Air-Thermodynamic Analysis. Int. J. Greenhouse Gas $470 \quad$ Control 2009, 3 (4), 376-384. 